\title{
The Issue of Normativity and the Methodological Implications of Interpretivism II: The Distinctive Normativity of Law
}

\begin{abstract}
The article is the second part of an analysis that seeks to clarify the distinctive normativity of law, as it is reflected in the legal systems of constitutional democracies. It explores the ability of interpretive theories to capture the conceptual characteristics of the normativity of law. The article argues that it is its institutional character that makes the normativity of law distinctive. The normativity of law must be construed as a form of institutional normativity. The analysis of the institutional character of legal norms revolves around the idea of obligations. It implies that the distinctive normativity of law builds on normative guidance by authoritative institutions. The ability of the law to provide normative guidance is explained in terms of three types of reasons: moral reasons, compliance reasons and response reasons. An implication of this insight is that moral legitimacy is constitutive of the normativity of law. The article concludes with an exploration of the dimensions of moral legitimacy in law, and the way the interplay of the justificatory background to normative claims and the institutional features of law make false normativity in law possible.
\end{abstract}

Keywords: interpretivism, normative guidance, authority, institutional normativity, moral legitimacy, false normativity

In Part I of this article, ${ }^{1}$ I have sought to lay the conceptual groundwork for an interpretive account of the normativity of law. That article offered a methodological programme, a clarification of the idea of normative guidance, and an analysis of normative claims in terms of practical reasons. In Part II, I seek to bring together the conceptual elements that have been elaborated there, and deploy them to provide an account of the distinctive normativity of law. I emphasise the fact that my main concern is testing the ability of interpretive legal theories to capture the conceptual characteristics of law. I explore the peculiarities, structures and limitations of interpretive theorising. Even when I give a different impression, this piece remains a predominantly methodological piece: the abstract demonstration of a methodological vision.

\section{The normativity of law}

\subsection{The prohibition of direct discrimination as a legal obligation}

It is useful to start with reminding ourselves of the original question that guided the analysis in Part I: what happens to a normative claim when it is written into the law? There, I chose the normative claim condemning direct discrimination (in the law of the United Kingdom) as the test case for my analysis. ${ }^{2}$ In Part I, I concentrated on the way the relevant normative claim can operate outside the context of law. In other words, I tested the capacity for normative guidance of the following claim: 'treating people less favourably just because

* Senior lecturer, University of Aberdeen, School of Law, Elphinstone Road, Aberdeen, AB24 3UF, United Kingdom.United Kingdom.

E-mail: m.bodig@abdn.ac.uk

1 See Bódig, M.: The Issue of Normativity and the Methodological Implications of Interpretivism I: The Idea of Normative Guidance. Acta Juridica Hungarica, 54 (2013) 2, 119-139.

2 See Equality Act 2010, ss. 13(1) and 39. 
they are of a different colour or gender is wrong: if we truly respect the moral equality of persons, we must stand up against discrimination.' Here, on the back of the analysis already provided, I look at the normative claim condemning direct discrimination as a legal norm.

If we compare the moral claim to the corresponding legal norm we find in Equality Act 2010, it is not hard to spot a few conceptually relevant differences. The most obvious is that the legal norm is embedded in the practice of a system of institutions. Those institutions bolster the normative claim with an enforcement mechanism ${ }^{3}$ that had no equivalent before.

Concentrating on this insight may seem to make our job of clarification relatively straightforward. At the beginning of my analysis in Part I, I promised to address the conceptual implications of the claim that 'law is a normative and institutional social practice.' One could think that, in Part I, I have dealt extensively with what 'normative' may mean in that sentence, and we can turn now to another conceptual ingredient: the way the 'institutional' character of law determines its conceptual features. But, of course, it would be a mistake to think that we deal with two separate conceptual features here. Institutionalisation has a comprehensive impact on the way normative claims guide action. It alters the conditions of what I characterised as the success and efficacy of normative claims (in sections 3.2 and 3.5 in Part I).

I submit that, if we want to get clearer about the character of the legal norm prohibiting direct discrimination, we need to focus not on the mere fact of its institutionalisation but on another salient feature of it: that it has created a legal obligation not to discriminate. ${ }^{4}$ (The reasons for choosing this focus will become clearer below.) Obligations can be seen as a subcategory of the general model of normative guidance I have analysed in Part I of this article (in section 2). They do not simply communicate expectations with a view to making an impact on the addressee's conduct. Obligations also involve establishing some normative ground for holding the addressees liable for acting on the relevant normative claims.

Some might think that the term 'obligation' is not the best conceptual focus for us here. In our example, some form of obligation (most plausibly a moral obligation) not to discriminate seems to have been there in the first place. The normative force of the legal obligation may be seen as derived from that 'underlying' obligation. ${ }^{5}$ But it does not mean that little has changed in terms of obligations with legal institutionalisation. The legal obligation is generated by a kind of explicit decision to make direct discrimination prohibited that is quite alien to the character of the relevant moral obligation. No one can claim that she has made it a moral obligation not to discriminate (the way the legislators in Westminster can about the corresponding legal obligation). The legal obligation here was purposefully created to generate specific normative ties between persons.

This point is vital to my analysis. It is underlined by the fact that the creation of legal obligations in Equality Act 2010 (just like in any other statute) follows a characteristic pattern. Statutory obligations are imposed on the addressees unilaterally and regardless of their specific consent. The conditions of success for normative claims that purport to create

3 See Equality Act 2010, ss. 113-126.

${ }^{4}$ The choice of terminology is not accidental here. The concept of 'obligation' (as opposed to 'duty') captures the relational aspect of normative ties: obligations are specific normative relations between parties. Cf. MacCormick, N.: Institutions of Law. Oxford, 2008, 109-115. It fits the way I have conceptualised direct normativity in Part I (subsection 2.3).

5 This may be an implication of the view (held by some legal theorists) that only morality can obligate. See e.g. Hurd, H. M.: Interpreting Authorities. In: Marmor, A. (ed.): Law and Interpretation: Essays in Legal Philosophy. Oxford, 1995, 425. 
obligations in this way invite a series of complex questions on how the law gains normative competence to obligate with unilateral acts. The interpretive data about legal obligations provide us with a conceptual focus for this inquiry. Someone must be a (practical) authority to be able to impose obligations on others by unilateral acts. ${ }^{6}$ (For example lawyers in Britain know that a statute like Equality Act 2010 could only come from the UK Parliament in Westminster.) What we are after is not simply normative guidance by institutions but normative guidance by authoritative institutions.

Understanding the kind of authority manifested in legal obligations is pretty much the key to clarifying the distinctive normativity of law. ${ }^{7}$ And there is an important clue about it in the interpretive data. The law is not the only authority that guides the addressees. ${ }^{8}$ The parent, the teacher, the spiritual leader and many others also have the capacity to impose obligations on certain addressees. It is an ever-present possibility that the addressee faces conflicting claims by different authorities. Following a certain course of action may be stipulated as an obligation by one authority but explicitly forbidden by another. ${ }^{9}$ It is revealing about the normative claims of law if we clarify how legal authorities are related to other authorities. And the available interpretive data suggest that the law addresses the possibility of conflicts by claiming a status of 'primacy' or 'superiority' over other normative practices. ${ }^{10}$ Legal institutions lay claim to determining the limits of the normative competence for rival authorities. ${ }^{11}$

It does not mean that the directives of other authorities must always give way to law. It does happen that the law opens up 'normative space' for obligations from other sources by limiting its own normative clout. But the point is that, in such situations, the law purports to limit itself. It is the legal authorities that lay claim to determining the weight of rival normative claims in areas where they have normative clout. ${ }^{12}$

${ }^{6}$ See Bódig, M.: Jogelmélet és gyakorlati filozófia. Miskolc, 2004, chapters 7 and 35.

7 This obviously invites questions on how my analysis is related to the concept of 'authoritative reasons.' For the two classical accounts of the concept, see Raz, J.: Practical Reason and Norms. 2nd ed., Princeton, N. J.,1990, 58-59; Hart, H. L. A.: Essays on Bentham. Oxford, 1982, 253-255. But I will not address that issue here. It is mainly because the compatibility of my account with the Razian idea of 'exclusionary reasons' (see Practical Reason and Norms pp. 40-45) would require a detailed analysis that I cannot provide here. I hope that I can make sense of the idea of institutionalised authority within the terminological framework I have at my disposal.

8 Cf. Raz, J.: Between Authority and Interpretation. Oxford, 2009, 143.

${ }^{9}$ An example could be the regulation of abortion. In many countries, professional rules require gynaecologists to perform abortions during their training, which is, of course, forbidden by the Catholic Church. For a Catholic gynaecologist, this can generate a clash of normative claims with very uncomfortable implications.

10 Cf. Finnis, J.: Natural Law and Natural Rights. Oxford, 1982, 148. Llewellyn, K. N.: The Normative, the Legal, and the Law-Jobs: The Problem of Juristic Method. Yale Law Journal, 49 (1940), 1355-1400, 1367. In a similar context, Neil Walker characterises the authority claims of law as 'magisterial'. See his 'Out of Place and Out of Time: Law's Fading Coordinates.' Edinburgh Law Review, 14 (2010), 13-46, 31-32.

11 The fact that this is an interpretive claim has special significance here. The claim to 'primacy' I talk about may reflect the way ideas of sovereignty took shape after the destructive religious conflicts of early modernity in Europe. Neil Walker argues that domestic law is losing its 'magisterial' character under the conditions of globalisation. See ibid. 44.

12 UK equality legislation provides instructive examples for this. It regulates a whole series of exemptions from obligations under the Act, and most of them are designed to accommodate the 
This claim of (normative) priority for legal authorities is even better reflected in the interpretive data we get from the most characteristic manifestation of legal justification: the legal dispute (as formalised in judicial procedures). One must think of legal procedures that revolve around the liability of particular persons, and in which the authoritative decision about liability emerges from a formalised practical debate between the parties. One of the characteristic features of such procedures is that the law pervasively determines the scope of the practical justification the parties can resort to. ${ }^{13}$ It determines, in many ways, what reasons are relevant for imposing liability on the parties, and what reasons can be constitutive of the decision-clearly manifesting the claim of normative superiority by the law. If we live under the normative clout of law, we face the prospect of finding ourselves in situations where important practical judgments on our behaviour are determined in this way.

\subsection{Institutional normativity}

After these preliminary remarks, we are better positioned to subject the normativity of law to a slightly more detailed analysis. The idea that guides our investigation is that, when written into law, the normative claim condemning direct discrimination has become institutionalised in a particular way: it was turned into an authoritative directive. The process of legal institutionalisation was driven by the fact that the normative claim was ‘appropriated' by particular authorities.

First, I would like to have a cursory look at how the fact of institutionalisation alters the way normative guidance works. (Later, I will try to figure out why it is necessary that authority claims drive the process of institutionalisation.) It seems that our best starting point for this is the observation that there is a fundamental instability built into the idea normative guidance (as depicted in my analysis). I have claimed in Part I (subsection 3.2), in order to be capable of normative guidance, a normative claim must be successful, and that a normative claim is successful if it changes the conditions of justifiability for the addressee's conduct. What we have to realise is that these characteristics leave normative guidance uncertain in a number of obvious respects. They do not provide a reliable way to tell whether a normative claim is successful in relation to each (targeted) addressee. The exact impact of the normative claim on the conditions of justifiability is also uncertain. And we have no secure way of ascertaining whether the addressee has managed to justify her actions in light of the relevant normative claim. All these issues can become a matter of

normative claims of other authoritative entities-like churches (see e.g. Equality Act 2010 s. 29). But the point is that such exemptions must be provided for explicitly. Without it, the law trumps other normative claims. This aspect of the normativity of law was brought into sharp focus recently by the 'Jewish Free School' case in the UK. See Regina (E) v Governing Body of JFS [2010] 2 A.C. 728. The UK Supreme Court ruled in the case that a boy who was not admitted to the pertinent school suffered ethnic discrimination (under Race Relations Act 1976). The Law Lords themselves were somewhat reluctant to trump the religious authority in this case but the relevant law very simply did not leave them a choice. See e.g. Baroness Hale’s complaints (at §§ 69-70) about the rigidity of the law when it comes to allowing for justified departures.

13 Cf. Fuller, L. L.: The Forms and Limits of Adjudication. Harvard Law Review, 92 (1978), 353-409, 369. 
controversy and drawn-out dispute. And these are exactly the uncertainties that plague our moral discourses. ${ }^{14}$

There is a feature of normative guidance that makes it pretty much inevitable that such uncertainties arise. The justificatory force of normative claims is inherently linked to the discourses in which the reasons constituting them are formed and made intelligible. They are bound to have limited impact on the behaviour of those who are not committed participants of the pertinent moral discourses. (As I have indicated in subsection 3.6 of Part I, this was pretty much the case with the norm condemning discrimination: it had limited impact on those not committed to a liberal moral-political discourse.)

We should also add that uncertainty is not the only source of instability built into the idea of normative guidance. Even if we do not get stuck with debates about the success of our normative claims, there is no systematic guarantee that they will be aligned with the prudential reasons of the addressees. They may be overridden by preferences that one has stronger motivations to act upon.

Quite obviously, these are practical difficulties that affect the conditions of both the success and the efficacy of normative claims. But the deficiencies in terms of efficacy may seem particularly problematic. They conspire to make it difficult to organise a consistent social practice around mere moral (and political) claims.

Institutionalisation addresses these problems, and promises to tackle the instability of normative guidance. The way I read the interpretive data about the characteristic legal institutions (like courts or law enforcement agencies), the hope that legal institutions make normative claims more practicable derives mainly from three of their conceptual 'ingredients'. The first is the constitution of institutional roles that make certain participants personally responsible for maintaining or enforcing normative claims. They become 'officials' who are specifically incentivised to facilitate compliance with the relevant normative claims (e.g. by pay and career prospects). The second conceptual ingredient is the construction of procedures in which assessing the conduct of the addressees in light of legal norms takes centre stage. In those procedures, the scope of the practical justification the addressees can resort to becomes closely tied to the relevant institutional norms. ${ }^{15}$ The third ingredient is that institutions rely on organised power. Institutions have human and other resources at their disposal that they can mobilise to add practical weight to normative claims.

This may sound like claiming that institutionalisation is all about added pressure on the addressees to comply. If one demands the legal institutionalisation of a norm prohibiting direct discrimination, she looks like striving to force upon others a normative constraint that they are reluctant to subscribe to (or comply with). Adding practical weight to the norms allows for neutralising the impact of controversies on compliance. Of course, it would be difficult to deny that this is an inevitable consequence of institutionalisation. But it is equally important to see that the real political attraction of legal institutionalisation lies in something else. Institutions have the potential to develop a largely uniform practice in which the conduct of all the addressees is consistently assessed in light of the same

14 Admittedly, these considerations refer back to Hart's analysis about the deficiencies of normative guidance through 'primary rules' only. See Hart, H. L. A.: The Concept of Law. 2nd ed., Oxford, 1994, 92-94. But I believe those considerations are contextualised better if they are related to the issue of institutionalising normativity.

15 I believe that this is the analytically most important manifestation of the authority of law. 
normative claims. Where moral and political controversies are pervasive features of public life, institutional norms offer the only chance to have an extensive body of common rules that may give a normative identity to a community. If one believes that we need a common rule that prohibits direct discrimination, it needs to be a legal one.

\subsection{The efficacy of law}

We need to be a bit clearer on how institutionalisation can bring about drastic improvement in efficacy. The challenge that requires a response is not that successful normative claims can completely lack efficacy without institutional backup. (A successful normative claim is always efficacious to an extent. ${ }^{16}$ ) The challenge is that most normative claims, purely on the strength of the reasons that make them successful, can attain only limited efficacy. The efficacy of successful normative claims is too dependent on the fit with the moral outlooks and the given prudential reasons of the addressees. Systematic and enduring improvements in efficacy can only be achieved through mobilising the action-guiding capacity of institutions.

In Part I (subsection 3.5), I have characterised the ability of normative claims to generate compliance in terms of three types of reasons: 'benefit', 'response' and 'moral'. 'Institutional normativity' can be construed as being built around the possibility of motivating people along the lines of these reasons. It does not mean that all of these reasons must play a role whenever someone complies with a directive. What it means is that, in terms of the efficacy of normative claims, a variety of reasons are at the law's disposal, giving it flexibility to adjust to the dynamics of social relations and individual attitudes.

\subsection{The success of the normative claims of law}

In light of what we already know about institutional normativity, it seems reasonable to think that it has limited capacity to add to the success of normative claims. No doubt, there is considerable moral attraction to having a common normative framework that has clearly defined boundaries patrolled by specialised institutions. ${ }^{17}$ But that attraction is limited to normative claims that are already successful: where the challenge lies in controversies about their exact scope or exact applications, and extending their normative scope to a broader cohort of addressees. In the fact of institutionalisation, there is nothing that would be capable of turning a wholly unsuccessful normative claim into a successful one.

There is a feature of the relevant interpretive data that point to this very conclusion. What has been said about the success of normative claims may have reminded some of my readers of the way the concept of validity is deployed in institutional settings. ${ }^{18}$ Legal validity may look like the specification of the conditions of success for legal norms. But it is not really the case. The very possibility of procedures like constitutional review (and the intelligibility of civil disobedience) indicates that meeting the institutional criteria of

16 If a normative claim is successful, there must be agents (by definition) who accept the justifying force of the underlying reasons, and there must be agents who find it important not to subvert the expectations manifested in them. These people are very much likely to comply.

17 This attraction may be strong for those who believe that one of the primary functions of law is to provide solutions to coordination problems. See e.g. Postema, G. J.: Coordination and Convention at the Foundations of Law. Journal of Legal Studies, 11 (1982), 165-203. Finnis, J.: Law as Coordination. Ratio Juris, 2 (1989), 97-104.

18 See Bódig: Jogelmélet és gyakorlati filozófia. op. cit. ch. 37. 
validity can fail to produce successful normative claims. Legal institutions can happen to enforce a norm that is widely acknowledged to be lacking the support of a proper background justification. Validity is not really an institutional reflection of the conditions of success-it is more like an institutional substitute for such conditions. Legal validity is one of the features of institutional normativity that help overcome the uncertainty over the scope of application for legal norms. It has more to do with efficacy than success.

In light of all this, it is not a surprise that legal institutions tend not to claim normative clout over the addressees simply on the basis of the organised power they wield, or by pointing to formal criteria of validity. They invariably build associations with legitimating discourses that link up the law with values like democratic credentials, public order and the common good. And, more importantly, they claim that there is good authority underlying the norms of law. ${ }^{19}$ (We can say that the criteria of validity are designed to trace the manifestation of the relevant authority-never to constitute it.)

In other words, if the norm prohibiting direct discrimination is made 'more successful' in the process of institutionalisation, it derives largely from the fact that authorities have thrown their weight behind it. I have argued in Part I (in subsection 3.2) that two types of reasons must come together to constitute a successful normative claim: reasons providing a justificatory background to the substantive normative qualification and reasons underlying the competence of those who make the normative claim. Institutionalisation in itself has little or no impact on the first aspect of the conditions of success but it profoundly reconstitutes the second one. In our example, the most important change that the normative claim condemning direct discrimination underwent lies in the fact that it came to represent the expectations of a (political) authority with comprehensive normative competence over the conduct of its addressees.

This may give the impression that, in the process of writing a normative claim into law, we witness two developments that are largely independent of each other: (1) the appropriation of the normative claim by an authority, and (2) mobilising institutional power to bolster instrumental reasons for compliance. One is concerned mainly with conditions of success, and the other with efficacy. But that is inaccurate. The connection is more intimate between the authoritative and institutional aspect of legal normativity. The improvements in efficacy I have outlined cannot be realised without turning normative claims into obligations. We know that non-legal normative claims often provide considerable normative guidance without constituting obligations: by giving advice or encouraging people to aspire for excellence. The case of institutional normativity is different. Interpretive data suggest that all forms of efficient enforcement of legal norms works primarily through imposing liability on the addressees. Without this, officials would not be able to single out addressees who are to be subjected to legal procedures, and much of the impact on the instrumental reasons of the addressees would be lost. The gains in efficacy institutions promise can be realised only through establishing a system of obligations. And one needs to be an authority to guide action by setting up a system of obligations.

19 That is why it is typical that legislative pronouncements come with a standard formula pointing to the authority manifested in the fact of enactment. In Equality Act 2010 (just like in any other UK statute), the formula is the following: ‘Be it enacted by the Queen's most Excellent Majesty, by and with the advice and consent of the Lords Spiritual and Temporal, and Commons, in this present Parliament assembled, and by the authority of the same, as follows...' (Italics are mine.) 
This is reflected in the fact that the form of legal institutionalisation tends to be structured by the character of the authority they manifest. Institutionalisation is driven by the assumption that the authority is justified in using power to bolster its directives. The power that institutions rely on is tailored to the authority they exercise. The use of organised power (to put pressure on the addressees to comply) only qualifies as an act of law if it is authenticated by authoritative pronouncements.

\subsection{Obligations and moral reasons}

One of the crucial implications of these considerations is that institutional normativity has a distinctive justificatory dimension. And we have reached the point in the analysis where we can get a bit clearer about this dimension. The point I want to highlight here is that prudential reasons alone simply cannot give rise to obligations. It can happen that we have strong prudential reasons to do something. It can also happen that we have prudential reasons to act upon an obligation. But having prudential reasons can never be enough to generate obligations. This consideration can be linked up with a conceptual point I have made in Part I (subsection 3.5). When we have an obligation to do something, it sets a normative standard (a 'liability') for us that remains, to a considerable degree, insensitive to the shifts in our perceived interests. Obligations have a characteristic non-instrumental element. Although obligations are often created with a view to achieving personal aims (it may be in my interest to enter a contract), they are not invalidated simply by a change in one's perceived interests. Normally, they are to be respected even when they become burdensome. By contrast, changes in our personal aims and perceived interests immediately reconfigure our instrumental reasons. Prudential reasons do not establish normative bonds that become (even partly) independent of one's perceived interests.

There are legal theorists (Hart among them) who argue that legal obligations are sui generis obligations whose character is conceptually different to that of moral obligations ${ }^{20}$ legal obligations can be generated in ways that moral reasons have nothing to do with. Of course, it is undeniable that legal obligations differ from moral obligations in important respects. (I have even emphasised this above.) However, it seems fundamentally mistaken (at least within the methodological framework that determines my perspective) to think that legal obligations can be generated without the justificatory background of moral reasons. It flies in the face of important interpretive data. In our legal practices, normative bonds that are detached from the perceived interests of the addressees are quite common. We cannot challenge the normative claim implied in a legal obligation by pointing out that we have no interest in acting upon it. Normally, when the issue of liability is raised in a legal procedure, it is irrelevant whether the addressee had prudential reasons to comply with the legal requirement. I cannot see how one can account for this feature of law if one denies the constitutive role of moral reasons in generating legal normativity. ${ }^{21}$ It seems

20 See e.g. Hart: Essays on Bentham. op. cit. 145-161.

${ }^{21}$ I note that this view presupposes the rejection of the legal positivist idea of 'social normativity.' See e.g. Hart: The Concept of Law. op. cit. 254-259. See also Coleman, J.: The Practice of Principle. Oxford, 2001, 69-71. Advocates of this strategy deny that moral reasons have a necessary place in the explanation of legal normativity. For my take on the issue, see my Jogelmélet és gyakorlati filozófia. op. cit. ch. 4. 
more plausible that the law can create obligations only with the justificatory background of moral reasons. ${ }^{22}$

\subsection{The problem of sanctions}

I believe that we are likely to arrive at the same insight about the constitutive role of moral reasons if we concentrate on the way response-reasons figure in the normative guidance provided by law. I have mentioned in Part I (in subsection 3.3) that reasons associated with coercion (i.e. reasons generated by legal sanctions) can be part of providing normative guidance-but only under specific conditions. That is, coercion must be imposed and applied by agents who are in a particular normative position. If we ask about the parameters of the position that qualifies someone to impose sanctions on others, we are unlikely to find convincing answers without pointing normative bonds that are independent of the perceived interests of the addressees.

It may be surprising that my account makes an explicit reference to the idea of 'sanction' so late in the analysis. Nothing seems to be more obvious that legal norms typically stipulate sanctions. But I deliberately held back the concept. Sanctions are not part of the basic structure of normative claims-not even legal ones. Sanctions generate what Raz helpfully terms 'auxiliary reasons ${ }^{\text {'23 }}$-they give extra practical weight to normative claims. This assumes that successful normative claims always have some normative force without sanctions. In fact, sanctions must be built on successful normative claims that have significant action-guiding capacity independently of them. If there is no successful normative claim that the sanction can be attached to, its imposition constitutes an act of mere coercion.

This is a claim that finds solid support in interpretive data. It is characteristic of the law to resort to sanctions but their application can only be legally appropriate when it is justified by pointing to a breach of legal obligations. (This is literally the only way in which legal sanctions can be deployed in a constitutional democracy.) Legal obligations are conceptual preconditions to legal sanctions. Hence, it must be possible to clarify the conceptual character of legal obligations without making reference to sanctions. I have tried to demonstrate in this analysis that such a clarification is indeed possible. And, of course, the key to getting the conceptual relationship between obligations and sanctions right is distinguishing between the conditions of the success and the efficacy of normative claims (that I developed in subsections 3.2 and 3.4 of Part I). Sanctions have a role (often an indispensable role) in making successful normative claims more efficacious-but they have not much to do with the circumstances that make normative claims successful.

22 Of course, on the basis of the limited analysis I have provided, it is impossible to clarify what would count as an adequate moral justification necessary to constitute a legal obligation. In fact, I do not think that there is a general answer to this question. It may be that, in most cases, what is required is no more than what Kenneth Himma has suggested: the law must be 'the type of thing that is minimally respectable from a moral point of view' to be able to give rise to obligations. See Himma, K. E.: The Ties that Bind: An Analysis of the Concept of Obligation. p. 32. Available at SSRN (http:// ssrn.com/abstract=924106).

${ }^{23}$ For the concept of 'auxiliary reasons', see Raz: Practical Reason and Norms. op. cit. 34-35. 


\subsection{False normativity}

The picture that is emerging in this section suggests that institutional normativity is mainly about closing motivational gaps-channelling behaviour by influencing motivations and bringing it within the range of justifiable actions. In this sense, the art of creating and administering law is based on the ability to identify and mobilise the motivations that produce actions that meet reason-based expectations. ${ }^{24}$ At the same time, as we have seen, institutional normativity cannot be all about efficacy-generating compliance. Institutional normativity must 'feed on' normative claims that are at least partly successful in the first place. This follows mainly from the fact that institutions cannot provide efficient normative guidance without imposing obligations on the addressees. Due to the conceptual character of obligations, support from moral reasons is bound to become a condition of success for institutionalised normative claims.

Of course, this is an insight with far-reaching and multifarious implications for the normativity of law. This is the insight that brings into focus the vexed issue of the moral legitimacy of law and its impact on the normative force of law. Pursuing this issue requires us to develop a better understanding of how the available interpretive data associate the law with political ideals and values that profoundly shape the perception of law by the participants of the practice. Of course, this is an issue that I cannot treat adequately here. As I have indicated in Part I (section 1), it is not because I believe that interpretive legal theory should leave such issues to normative political theory. Interpretive analysis can and should extend to political values that are constitutive of legitimating discourses systematically linked to the legal practice. The reason for stopping here is that this is a methodological implication that I chose to set aside in this particular investigation.

However, there is one aspect to the interplay between legal normativity and the conditions of success for normative claims that I can point out here. And I must point it out here to complete the present analysis. I have emphasised above that legal institutions have their ways of addressing the conditions of success for their normative claims. Most importantly, they are constituted as authoritative institutions that purport to have the normative competence to make their addressees liable for complying with the law. But we should not forget that the conditions of success are twofold: there must be reasons providing a substantive justificatory background to the pertinent normative claim, as well as reasons that underlie the claimants' competence. What we have to realise is that, although the authority claims of legal institutions directly touch upon the competence dimension of normative claims, they can have little impact on the substantive justificatory background. Appropriation by authority does not make a normative claim substantively more justified.

Legal institutionalisation in itself provides no cure for the possible deficiencies of the substantive justification for the normative claims. And the inevitable consequence of this is that institutionalisation opens up the possibility that the law produces what we might call 'false normativity': generating compliance with (partly) unsuccessful normative claims. Moreover, it is reasonable to think that false normativity is not just a possibility. Considering that the reliance on legal normativity is necessitated partly by the fact of moral and political

24 As the reasons which provide the background justification for the expectations must be reasons for the addressees to constitute normative guidance, I believe that Raz's 'service conception of authority' is fundamentally plausible. See e.g. Raz, J.: Ethics in the Public Domain. Oxford, 1994, 214. 
disagreement, ${ }^{25}$ it would be unrealistic to think that it is not one of the systematic features of law that people are, at least occasionally, forced to act in ways that are not justified from their perspective. ${ }^{26}$ False normativity is a characteristic feature of the legal mechanisms I reflect on.

I believe that it is the issue of false normativity that ultimately determines the character of the problem of the moral legitimacy of law. It is by reflecting on this issue that helps us capture the exact sense in which legal normativity inevitably has a dark side, and embracing institutional normativity in a community comes with a particular moral burden. It also indicates that, by stating that the law has the capacity for genuine normative guidance, one does not imply that the law is free of moral tension and even oppression. What it implies instead is that the inevitable deficiencies of its moral justifiability have a tendency to erode the ability of law to provide normative guidance. The law cannot maintain its ability to provide normative guidance without building functional links with moral and political discourses that have the potential to 'legitimize' and to generate momentum for institutional changes that address the challenges to legitimacy. Managing issues of legitimacy is part of the everyday life of legal systems.

\section{Conclusion}

I have dedicated this two-part analysis to the exploration of the character of interpretive theorising about law. It started with outlining three methodological points: interpretivism makes general theories of law problematic, interpretive analysis needs to extend beyond the traditional issues of conceptual legal theory, and it renders theories 'doubly' contingent. I have set aside the first two points to be able to deal with the third one in some detail.

I have claimed that interpretive theories are forced to accept the possibility of developing a number of potentially equally plausible accounts of the conceptual characteristics of law. My own analysis has put together one account of the normativity of law from a narrow set of interpretive data and a few conceptual devices floating around in contemporary mainstream legal theory. I have characterised normative guidance in terms of the impact practical reasons have on intentions in discursively constituted social interactions. In this framework, the claim that the law is normative means that it guides behaviour by making an impact on the practical deliberations of its addressees. I put the concept of normative claims at the centre of my analysis of normativity, and characterised them as reason-based expectations on the addressees' conduct. The internal structure of normative claims were analysed in terms of the conditions of success and efficacy for normative claims. The success of normative claims has two dimensions: their substantive background justification and the competence of those who make the pertinent normative claims. The efficacy of normative claims (that is, their ability to generate compliance) was broken down to the ability to provide three types of reasons: 'moral', 'benefit' and 'response' reasons.

The distinctive normativity of law was characterised against the background of the idea of institutional normativity. I have argued that the type of guidance the law provides brings obligations into focus. Legal obligations presuppose an authority structure without

25 Cf. MacCormick: op. cit. 245. For a more substantial analysis, see Waldron, J.: Law and Disagreement. Oxford, 1999.

${ }^{26}$ One can claim that false normativity has infected the 'Jewish Free School' case that I have mentioned above. See supra note 11 . 
which the normative claims of law cannot be successful. The conceptual character of obligations was analysed in terms of both instrumental and non-instrumental reasons, and it pointed to a conceptual link between the law's ability to impose obligations and its moral legitimacy.

Admittedly, my account of the distinctive normativity of law is under-determined, and relies extensively on definitional fiat. The substantive account of normativity I provide does not offer a general paradigm for legal theory: it is just one contingent example for the way normative theorising works. But I believe it has considerable explanatory force, and it promises some progress in integrating doctrinal perspectives on law with contemporary mainstream legal theory. 